\title{
ESTRATÉGIAS DE EDUCAÇÃO AMBIENTAL POR MEIO DA ATUAÇÃO DA COM-VIDA: VIVÊNCIAS EM UMA ESCOLA DO RECIFE-PE
}

\author{
J.F.F. Camboim ${ }^{1}$ e A. G. Barbosa ${ }^{2}$ \\ ${ }^{1}$ Graduada em Tecnologia em Gestão Ambiental e Graduanda em Pedagogia \\ ${ }^{2}$ Graduado e Mestre em Geografia. Doutorando em Geografia. Professor do IFPE \\ jackelinecamboim@yahoo.com.br-adauto@recife.ifpe.edu.br
}

Artigo submetido em dezembro/2011 e aceito em março/2012

\section{RESUMO}

A Educação Ambiental (EA) é abordada numa visão crítica e contextualizada nas ações da Comissão de Meio Ambiente e Qualidade de Vida na Escola (COMVIDA) em uma escola da Rede Municipal da cidade do Recife (PE). Sob o aspecto teórico, a pesquisa trabalha com a noção de sujeito ecológico. A partir das vivências e ações, são destacadas dificuldades e novos horizontes da atuação da COM-VIDA, na perspectiva da formação do sujeito ecológico. Trata-se de uma pesquisa qualitativa, cujos sujeitos pesquisados foram estudantes e estagiários que atuaram na referida comissão. Foram utilizados os seguintes instrumentos de pesquisa: observação, entrevista, aplicação de questionário e realização de oficinas. Os resultados da pesquisa mostraram que as ações da COM-VIDA podem facilitar a integração de toda a comunidade escolar. As atividades desenvolvidas de forma prática despertaram nos estudantes maior interesse pelos conteúdos e deveriam ser trabalhadas de forma interdisciplinar. Verificou-se, porém, que há ainda muito a se avançar no processo de ensinoaprendizagem, de maneira a integrar as estratégias de EA, fomentando uma ação interdisciplinar na escola.

PALAVRAS-CHAVE: Escola, COM-VIDA, Meio ambiente, Educação ambiental, Sujeito ecológico.

\section{STRATEGIES OF ENVIROMENTAL EDUCATION THROUGH PERFOMACE OF COM-VIDA: EXPERIENCES AT A SCHOOL FROM RECIFE-PE}

\section{ABSTRACT}

The Environmental Education is approached under a critical view and contextualized in the actions of Comissão de Meio Ambiente e Qualidade de Vida na Escola (COM-VIDA) at a school of the public system in Recife. On the theoretical side, the research deals with the notion of ecological person. Based on the experience and actions difficulties and new horizons of perfomace of the COM-VIDA are highlighted, under a perspective to the formation of the ecological person. In order to attend a qualitive search, whose subjects were students and trainees that worked on the committee; we used the following tools: observation, interviews, questionnaires and workshops. The results of the survey showed that the actions of COM-VIDA may facilitate the integration of the entire school community. The activities in a practical manner aroused great interest among students and the content should be worked in an interdisciplinary way. It was verified, however, that there is still much to advance the process of teaching and learning in a way to integrate the Environmental Education strategies, fostering an interdisciplinary action at school.

KEY-WORDS: School, COM-VIDA, Evironment, Environmental Education, Ecological person. 


\section{ESTRÁTEGIAS DE EDUCAÇÃO AMBIENTAL POR MEIO DA ATUAÇÃO DA COM-VIDA: VIVÊNCIAS EM UMA ESCOLA DO RECIFE-PE}

\section{INTRODUÇÃO}

O presente artigo é resultado de um Projeto do Programa Institucional de Iniciação Cientifica (PIBIC) e do Trabalho de Conclusão de Curso (TCC) de graduação e aborda a Educação Ambiental (EA) numa visão transformadora e crítica. Está contextualizado na análise das vivências da Comissão de Meio Ambiente e Qualidade de Vida na Escola (COM-VIDA) da Escola João XIII, pertencente à Rede Municipal da Cidade do Recife (PE) e, com base nelas, discute avanços e dificuldades, sobretudo no que se refere à formação do sujeito ecológico.

A escola é uma instituição social que tem a finalidade de socializar o ser humano, além de contribuir para o desenvolvimento de outras habilidades. Nesse sentido, a sociedade também deve atuar no processo educacional e as questões ambientais precisam fazer parte das atividades escolares. Abordar a temática ambiental tem sido um dos principais desafios do processo educacional, sobretudo sob o viés de uma EA crítica, contextualizada na realidade dos estudantes. Tal postura significa oferecer aos estudantes mais do que "chuvas" de conceitos, é preciso contextualizá-los em seu dia a dia buscando as contribuições de todos os componentes curriculares.

A criação da COM-VIDA derivou de proposta da I Conferência Infanto-Juvenil pelo Meio Ambiente, em 2003, por meio do documento "Jovens Cuidando do Brasil", defendendo a criação de espaços de participação em defesa do Meio Ambiente nas escolas. Assim, a COMVIDA é uma resposta a esse pedido. As escolas do ensino básico têm a missão de implantar suas comissões, que devem funcionar de forma a integrar todos os componentes curriculares e envolver toda comunidade escolar, inclusive, se possível, os pais dos estudantes e a vizinhança da escola.

O principal papel da COM-VIDA é realizar ações voltadas à melhoria do Meio Ambiente e da qualidade de vida, promovendo o intercâmbio entre escola e comunidade, além, de contribuir para um dia a dia participativo, democrático, animado e saudável. Logo, os objetivos dessa nova organização nas escolas são: a) desenvolver e acompanhar a EA na escola de forma permanente; b) ajudar a cuidar do Brasil, assumindo como orientação a Carta das Responsabilidades "Vamos Cuidar do Brasil"; c) fazer a Agenda 21 na escola (BRASIL, 2007, p. 15). Ela se pauta numa integração não apenas de professores com os estudantes, mas de toda a comunidade, fazendo com que a identidade da escola seja construída, e ao mesmo tempo, os participantes dessa construção se percebam enquanto sujeitos.

Sob o ponto de vista legal, é destacado pela Constituição Federal (CF) que o Meio Ambiente constitui um direito de todos, sendo dever da sociedade e do Estado sua conservação (Cap.VI, Art. 225). Deve ser destacada ainda a relação dos Parâmetros Curriculares Nacionais (PCNs) com esse fragmento da CF, quando diz que "a construção de um mundo socialmente justo e ecologicamente equilibrado requer responsabilidade individual e coletiva. (BRASIL, 1998, p.181).

Dessa forma, podemos perceber que tanto a CF quanto os PCNs falam sobre um mundo ecologicamente equilibrado. Porém, enquanto a CF tem por foco no poder público, os PCNs mostram que chegar a esse estágio é uma responsabilidade de cada indivíduo, ou seja, de cada cidadão de mundo. 
A integração entre a escola e a sociedade é aspecto absolutamente essencial. A Lei de Diretrizes e Bases da Educação Nacional (LDB) ressalta a criação de processos de integração da sociedade com a escola devem assegurar a participação da comunidade na gestão das escolas, a partir das comissões escolares ou órgãos equivalentes. Assim, os marcos legais apontam a preocupação em relacionar a Educação como dimensão da sociedade, que deve ser tratada não apenas como obrigação do Estado, mas como dever da sociedade, e de forma mais direta de toda a comunidade escolar.

A Agenda 21 Global é outro instrumento jurídico que destaca a importância da participação dos jovens nos processos de tomada de decisão relativos ao Meio Ambiente (Cap. 25. Art.9ㅇ Alínea a). Por sua vez, a PNEA, estabelece que "Como parte dos processos educativos mais amplos, todos têm direito à Educação Ambiental" (Art. 3ํ). Esse aspecto da participação está intimamente relacionado com a atuação da COM-VIDA, com o chamamento do engajamento da sociedade civil organizada, tendo em vista que a COM-VIDA é parte constituinte desse processo.

Os PCNs reforçam que "para que os alunos construam a visão da globalidade das questões ambientais é necessário que cada profissional de ensino, mesmo especialista seja um dos agentes da interdisciplinaridade que o tema exige" (BRASIL, 1998, p. 193). Assim, a interdisciplinaridade é de fundamental importância para a construção de um conhecimento sólido, além de fazer com que os estudantes se tornem sujeitos mais críticos diante de suas realidades e um dos espaços que podem ampliar as condições para tal prática políticopedagógica é a COM-VIDA, sobretudo no campo da EA.

\section{O SUJEITO ECOLÓGICO COMO UM ASPECTO TEÓRICO ESSENCIAL}

O campo ambiental na concepção de CARVALHO (2008) é essencialmente interdisciplinar, uma vez que a interdisciplinaridade é uma integração de vários saberes que levam a uma simples comunicação ou um diálogo amplo e aprofundado (FAZENDA, 1994). Esses diálogos estabelecidos no campo ambiental são de várias ordens e integram um complexo que apresenta a ideia de um tecido, isto é, que une vários elementos interligados. Tal interligação forma uma teia ou uma rede dentro de redes (CAPRA, 2006). Enfim, no campo ambiental, o sujeito encontra-se em um entrecruzamento social, histórico e cultural.

Nesse sentido, a EA é importante no que se refere à emergência do campo ambiental, tendo em vista que ela tem caráter humanístico, holístico e interdisciplinar e utiliza metodologias com base científica. A EA é um processo educacional em sentido amplo que fomenta novas sensibilidades e dá a sociedade uma visão que o Meio Ambiente é um espaço de relações, um campo de interações, sejam elas culturais, sociais e naturais.

A EA deve ser encarada como uma prática social, tendo em vista que a sua intenção é, no aspecto humanístico, fazer com que o homem use os seus saberes para as reais necessidades da sociedade. Propõe o ideal de respeito entre o homem frente ao natural, ou seja, que o homem perceba que ele sem o natural não pode fazer nada, já que os elementos dependem intrinsecamente uns dos outros, sejam eles artísticos culturais ou científicos.

A compreensão dessa conexão das redes pode ser alcançada na perspectiva do sujeito ecológico. O sujeito ecológico não são propriamente os integrantes de movimentos ecológicos. É evidente que eles podem assumir tal postura, mas também compreende aqueles 
que aderem a novos hábitos voltados para um maior respeito com o Meio Ambiente. A ação desse sujeito é orientada pelo ideário ecológico, que leva a um novo estilo de vida com modos próprios de pensar o mundo e, principalmente, de pensar a si mesmo e a relação com os outros nesse mundo (CARVALHO, 2008).

O sujeito ecológico é um ser de ideários utópicos, que vive na constante busca da perfeição (GOMES, 2010). De acordo com Boff, (1999, p.81) "o ser humano e a sociedade não podem viver sem utopia". Essa utopia faz com que sejamos seres humanos melhores, vivamos em busca de novos valores que regem a sua vida. Um ser utópico não é um ser sonhador, mas, um ser que está sempre a um passo à frente daquilo que deseja que seja real. As vivências apresentadas e discutidas neste trabalho mostram que a perspectiva do sujeito ecológico ainda se apresenta no plano da utopia, mas, como está posto acima, a utopia é o horizonte das ações e possibilidades da EA.

\section{PROCEDIMENTOS METODOLÓGICOS}

A pesquisa foi baseada em dados qualitativos envolvendo a experiência dos estudantes da Escola Municipal João XXIII, localizada no Bairro da Iputinga, cidade do Recife-PE, como parte das atividades da COM-VIDA. Inicialmente, foi feito o levantamento bibliográfico sobre aspectos teóricos da pesquisa, tais como: EA formal e não-formal, sujeito ecológico e temas transversais.

Apesar da abordagem qualitativa, alguns dados quantitativos foram necessários para a caracterização do quadro empírico da escola. Os sujeitos pesquisados foram os estudantes e os estagiários integrantes da COM-VIDA. Os instrumentos utilizados foram a observação, a entrevista, a aplicação de questionário e a realização de oficinas.

As entrevistas foram realizadas com três estagiários do projeto e, tendo em vista suas intencionalidades, tiveram a finalidade de identificar como as estratégias de EA realizadas pela COM-VIDA contribuíam na formação do sujeito ecológico. A análise do conteúdo obtido por meio das observações e das entrevistas foi apoiada em Bardin (1977). O questionário foi composto por cinco perguntas as quais foram respondidas pelos estudantes participantes do projeto e teve por objetivo identificar as percepções de EA nas estratégias da COM-VIDA. As respostas obtidas a partir dos questionários foram comparadas entre si, buscando identificar as respostas que apresentavam coincidências e as que eram diferentes. Após analisados, os dados dos questionários foram tabulados e apresentados em gráficos, conforme constam no item a seguir sobre os resultados e discussão.

As oficinas de EA que compuseram as ações da COM-VIDA na escola foram: pintura do Mural; construção de caixa de papel para a feira de reutilização; visita ao Jardim Botânico do Recife-PE; excursão no barco escola pelo Rio Capibaribe; e produção de sabão.

Durante a coleta dos dados encontramos algumas dificuldades já que elas não aconteciam ativamente por falta da participação contínua por parte da estagiária do projeto na escola pesquisada, e, portanto, os dados não poderiam ser coletados.

\section{RESULTADOS E DISCUSSÃO}

Neste tópico, apresentamos as estratégias de EA, destacando tanto seus aspectos positivos, quanto as dificuldades e desafios a enfrentados. Essa dupla visão pode contribuir 
para novas ações de EA em situações similares, sendo por isso importante destacar não somente os aspectos considerados positivos, como também os negativos e desafiadores.

\section{Da boa receptividade ao "balanço positivo" COM-VIDA}

Diante de inúmeras dificuldades enfrentadas pelos educadores no processo de ensinoaprendizagem, a grande aceitação por parte dos estudantes em participar de ações dessa natureza é sem dúvida um primeiro aspecto positivo da COM-VIDA. Desde já, ressaltamos que as dificuldades enfrentadas não resultam propriamente de alguma resistência dos estudantes, pois eles são os maiores entusiastas de atividades de caráter prático e interdisciplinar desenvolvidas na escola. Metodologias educativas como a COM-VIDA direcionam para a formação do sujeito ecológico. Os novos hábitos podem ser estimulados através daquilo que é visto no cotidiano, conforme verificamos na fala do sujeito 1: " Na COM-VIDA [nós] não aprendemos apenas sobre o Meio Ambiente, mas, de responsabilidade que a gente ver no dia a dia nos jornais, a gente coloca em prática."

E para que as metodologias usadas na COM-VIDA direcionem para a formação de sujeitos ecológicos é necessário a figura do educador como mediador desse processo. Contudo, conforme afirma Guimarães $(1995$, p. 30) "o educador deve tomar cuidado para não se colocar na posição pessimista em que alguns já afirmam: o homem definitivamente rompe o equilíbrio ecológico e seria melhor deixar de existir", é imprescindível que ele enquanto educador, apesar de saber que a crise ambiental existente é fruto da insensatez da humanidade, precisa agir de forma otimista, inclusive em sala de aula.

Esse aspecto da postura do educador e como ela pode interferir na postura do estudante foi verificado na fala do sujeito 1: “ [...] A postura do aluno depende da postura do professor, porque é a gente que vai passar para eles que aquilo é importante, que faz parte do dia a dia. Se você tiver uma postura confiante naquilo que você está fazendo, com certeza vai dar mais confiança para eles e pode trabalhar melhor." É importante ressaltar, que a postura do educador deve ser aquela que mostre aos estudantes, de forma prática e não apenas na teoria, valores fundamentais para a sociedade, acreditando e, mais que isso, incorporando como prática do seu cotidiano. Isso passa por uma permanente discussão sobre o currículo escolar, sobretudo questionando se os conteúdos são trabalhados de forma integrada entre os distintos componentes curriculares.

Outra contribuição da COM-VIDA é a possibilidade de uso de procedimentos didáticos fora da sala de aula, em que o cotidiano da escola pode ser vivenciado não apenas pelos estudantes, como também pelos pais e pela vizinhança. Tal integração não é fácil, conforme constatamos na escola estudada, mas essa dificuldade pode ser superada. A fala do sujeito 2 aponta essa perspectiva ao dizer que "A COM-VIDA é vista como uma possibilidade de saída do tradicional ensino de sala de aula, a gente tem a possibilidade, porque em sala de aula os alunos têm a oportunidade de produzir tudo que eles têm a capacidade, a COM-VIDA dá essa oportunidade ao aluno nessa descoberta da criatividade dele quando ele tiver a oportunidade dele expor essa criatividade em outro formato, hoje a Educação formal não dá essa oportunidade ao aluno em desenvolver outras habilidades que não seja atividades específicas das disciplinas. Não tem interdisciplinaridade."

A observação feita pelo entrevistado de que, a Educação formal é um espaço para a criatividade, pode ser interpretada como uma crítica do mesmo frente às enormes 
dificuldades enfrentadas pelos professores no processo ensino-aprendizagem. Esse fato se dá devido às carências que são comuns às nossas escolas. Contudo, também sabemos que a Educação formal pode e deve ser um espaço para a interdisciplinaridade. Dessa forma, Fazenda (1994) afirma que a prática da interdisciplinaridade não deve ficar apenas no campo das intencionalidades, mas, deve de fato ser concretizada e promover um encontro de indivíduos e não de disciplinas.

Projetos didáticos como a COM-VIDA podem ser uma das formas de construir o conhecimento. Estagiários entrevistados ressaltaram como aspecto positivo da COM-VIDA o fato de constituir um espaço de socialização dos estudantes e um conhecimento dos mesmos em termos de valorização de si próprios e dos outros. Sobre esse aspecto, um dos estagiários entrevistados afirmou: "Quando os projetos saem do papel, eles proporcionam uma mudança nos alunos que antes eram rebeldes, tendo em vista que os alunos encontram-se assim, porque não é dada uma oportunidade a eles. E quando se dá essa oportunidade, você observa que existe uma mudança real de comportamento, de atitude, com certeza isso tem acontecido através das atividades da COM-VIDA". Desse modo, a abertura de oportunidades pode transformar o estudante que, ao ser transformado, poderá transformar a sua realidade.

Uma das vivências da COM-VIDA na escola estudada é atuar é por meio da gincana de coleta seletiva proposta pela Empresa de Manutenção de Limpeza Urbana (EMLURB). Essa estratégia de EA contou ainda com o apoio de outros órgãos públicos municipais, como a Secretaria de Serviços Públicos, de Educação, Meio Ambiente e Ciência e Tecnologia, dentre outros parceiros. O papel da COM-VIDA foi mobilizar a escola para a gincana. Foi destacado como aspecto mais positivo da realização da gincana o fato de a coleta seletiva ter continuado na escola. Os estudantes passaram a trazer os recicláveis para a escola que se encarregou de levar para associação de catadores. Essa continuidade foi bem vista pelo estagiário como foi percebido na seguinte fala: "[...] vejo essa continuidade como uma coisa muito boa" (sujeito 2). Esse salto qualitativo representa o que pode-se chamar de mais um "balanço positivo" das ações da COM-VIDA na escola estudada.

Considerando resultados como esse, alguns sujeitos pesquisados relataram que as ações da COM-VIDA se transformam em efetiva mudança de atitude. A esse respeito, uma estagiária foi enfática ao afirmar que "Os alunos são mais participativos e menos agressivos" (Sujeito 3), entendendo esse maior nível de participação como maior interesse e engajamento nas atividades.

Outras estratégias de EA trabalhadas pela COM-VIDA na escola foi a realização da feira de reutilização e a oficina baseada num concurso de desenho que tinha como tema $A$ natureza em nós. Essas atividades tiveram a intenção de fazer com que os estudantes resgatassem suas lembranças e emoções para representarem em desenhos as suas percepções sobre o Meio Ambiente, além de estimular a arte. De acordo com a estagiária entrevistada, o objetivo era que os estudantes olhassem o Recife por outro ângulo, isto é, a partir do Rio Capibaribe, que corta a área central da cidade e constitui elemento essencial da paisagem recifense. Ao observar in loco o lixo jogado no leito do rio e observar a cidade dia a dia "sufocando-o", o intento era a sensibilização dos estudantes para a necessidade de preservar o Rio Capibaribe, sem perder de vista os bairros do Recife que o margeiam. Ao ver a poluição e o assoreamento de perto, é possível uma reflexão crítica o papel de cada um de nós na busca de minimizar esses problemas envolvendo o rio e a cidade. Quando isso se 
traduzir em ações efetivas de respeito ao Meio Ambiente, teremos o sujeito ecológico em toda sua expressão.

\section{As dificuldades e desafios e limites da ação}

Um dos maiores problemas identificados no âmbito das ações da COM-VIDA na escola João XXIII é a frágil participação do corpo docente nas atividades. Assim, a abordagem do tema Meio Ambiente de forma interdisciplinar ainda se apresenta como meta a ser atingida. Por outro lado, isso mostra a necessidade de que o trabalho da COM-VIDA tenha continuidade e seja permanentemente repensado. Como já foi dito, a Educação trabalhada numa perspectiva transformadora tem forte componente de utopia.

A análise do questionário demonstrou que os estudantes, em sua maioria, veem o Meio Ambiente reduzido à dimensão da natureza, como se a sociedade não fosse um de seus componentes. Outra percepção de Meio Ambiente identificada no discurso dos sujeitos foi a que encara sob a perspectiva funcionalista / reducionista, ou seja, a importância do Meio Ambiente é atribuída ao fato de dependermos dele para suprirmos nossas necessidades. Essa segunda perspectiva é consonante com a perspectiva dominante no Ocidente, de procurar ver se há utilidade nas coisas para justificar sua preservação. Não se considera, por exemplo, que os elementos naturais que compõem o Meio Ambiente têm um valor imanente e por isso deveriam ser conservados não só por servirem de recursos para a sobrevivência humana.

Sobre a perspectiva naturalista, Carvalho (2008, p. 35) afirma que "o conceito de Meio Ambiente numa visão "naturalizada" tende a ver a natureza como o mundo da ordem biológica, boa, pacífica, equilibrada, estável em suas interações ecossistêmicas, o qual segue vivendo e independente da interação com o mundo cultural humano". E uma das formas recorrentes de visão reducionista de Meio Ambiente é considerá-lo como sinônimo de natureza. É claro que a natureza é um dos principais componentes do Meio Ambiente, mas, não é o único. A natureza deve ser encarada como em permanente dinamismo e suas transformações são cada vez mais afetadas pelo homem.

Em relação a essa perspectiva reducionista, Gonzales e Silva (2004) afirmam ser ela bastante fragmentada, tendo em vista que reduz o Meio Ambiente a fenômenos, tais como, o ar que respiramos, a camada de ozônio, entre outros. É evidente que esses fenômenos também fazem parte e são indispensáveis para o Meio Ambiente. Contudo, não enxerga sua complexidade, já que é um todo e não uma parte ou um fragmento.

A partir da análise do questionário, verificou-se que as percepções dos estudantes em relação ao Meio Ambiente se enquadraram na visão naturalista, isto é, o veem apenas sob o ponto de vista da natureza e seus aspectos biológicos, como podemos inferir do exame do gráfico a seguir, sobre percepções de Meio Ambiente (Gráfico 1).

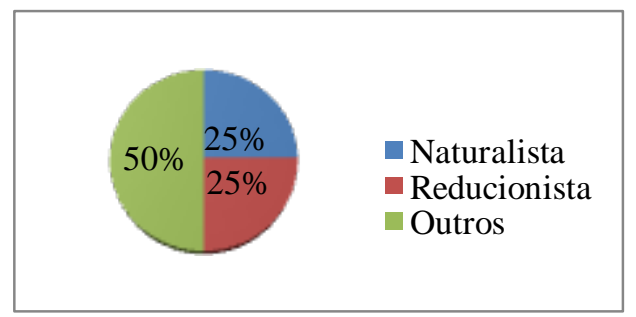

Gráfico 1: Percepções de Meio Ambiente. 
Apesar de os estudantes estarem participando da COM-VIDA, a qual em teoria promoveria uma visão de Meio Ambiente como instância em que natureza e sociedade seriam inseparáveis, constatamos que, contraditoriamente, as estratégias de EA não proporcionaram aos estudantes se verem como integrantes do Meio Ambiente. Por outro lado, $25 \%$ dos estudantes pesquisados conseguem construir uma melhor concepção de Meio Ambiente. Ao referir-se ao Meio Ambiente da seguinte forma: "o Meio Ambiente é vida", podemos inferir que de alguma forma ele concebe que sua vida depende do Meio Ambiente.

Outra questão levantada na pesquisa foi em relação à concepção de EA dos estudantes. Assim, verificamos que $25 \%$ dos estudantes veem a EA como uma maneira de conservação/preservação do Meio Ambiente; $25 \%$ conceituou a EA como uma forma de melhorar o Meio Ambiente. Outros $25 \%$ não souberam dizer o que era a EA, como ficou claro na seguinte fala "Ainda não sei sobre isso" (estudante 1 ). Outros $25 \%$ generalizaram o conceito, como foi percebido na seguinte fala: "são tantas coisas" (estudante 4).

É importante salientar os termos preservação e conservação foram considerados como sinônimos, embora sejam conceitualmente distintos. Preservação se refere à manutenção do Meio Ambiente de forma intocada, enquanto conservação se refere ao uso sustentável e racional dos recursos naturais. Obviamente, os estudantes aqui pesquisados não devem dispor ainda de aporte conceitual para estabelecer tal diferença, e, por conta disso, utilizou-se os dois termos de maneira indistinta. Como identificamos no gráfico abaixo sobre a concepção de EA dos estudantes. (Gráfico 2).

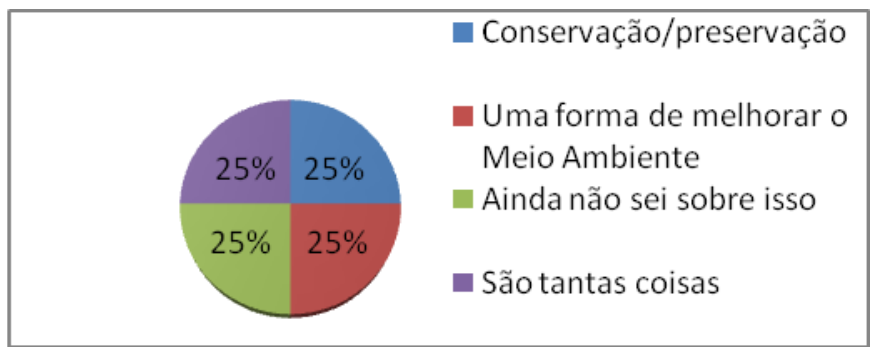

Gráfico 2: Concepção de Educação Ambiental

A despeito de a experiência da COM-VIDA precisar melhorar seus enfoques pedagógicos e buscar integrar suas ações com as estratégias didáticas dos vários componentes curriculares, mesmo assim, sua experiência tem gerado uma sensibilização dos estudantes em relação à EA. Outro fator que contribui para que os estudantes não saibam dizer com clareza o que seria a EA e os seus princípios éticos, é quando falamos de suas questões conceituais e epistemológicas e como elas deverão ser desenvolvidas por parte dos professores. Isso tem por consequência uma abordagem equivocada pelos mesmos, isto é, a forma como EA é trabalhada em sala de aula. Um desses equívocos é enxergar a EA como algo fora do contexto escolar, que deveria envolver os componentes curriculares e ainda a visão fragmentária já discutida.

Esse aspecto se dá em virtude da formação dos professores, que, muitas vezes, não os capacita para atuar em projetos ambientais (MENDES, 2010). Dessa forma, as instituições de ensino superior, devem ter por foco a questão da docência, contemplando, inclusive, projetos voltados para temática ambiental, para que os professores depois de formados, tenham uma visão crítica da realidade ambiental. Além disso, é preciso repensar o currículo. Parte dos 
desafios enfrentados pela COM-VIDA se deve a não integração dos professores, tradicionalmente "amarrados" aos conteúdos dos livros didáticos, com dificuldade em fazer maiores contextualizações com a realidade vivenciada cotidianamente pelos estudantes.

Indagamos também, aos estudantes da COM-VIDA, se eles gostam de participar do projeto e por quê. A análise do questionário mostrou que os estudantes veem a COM-VIDA como algo prazeroso e divertido. Verificamos que $100 \%$ dos estudantes afirmaram gostar de participar da COM-VIDA, no entanto, ao serem questionados sobre o por quê, os mesmos deram as seguintes respostas: "Porque nós fazemos feira de ciência" (estudante 1); "Eu gostei muito, têm muitas coisas, é muito divertida" (estudante 2); "Porque é muito legal, é muito bom"(estudante 3). Constatamos por essas respostas vagas que os estudantes estão participando da COM-VIDA, mas, não sabem exatamente o por quê de estarem ali. A despeito dos aspectos positivos apresentados no item anterior, fica claro que há muito ainda para avançar.

Outra questão levantada foi em relação à ação que os estudantes gostaram. Nesse sentido, $50 \%$ dos estudantes responderam que foi a ida ao Jardim Botânico; $25 \%$, a minifeira; outros $25 \%$, o concurso de desenho. Práticas como a oficina da minifeira são importantes, tendo em vista que os estudantes expõem a sua criação, fazendo e fiquem orgulhosos de si mesmos. Porém, é importante ressaltar a metodologia utilizada para essa atividade, é preciso que se tenha claro os reais objetivos da sua realização, senão irá se tratar apenas de mais uma oficina. O gráfico abaixo exibe o grau de preferência dos estudantes em relação a três estratégias de EA (Gráfico 4).

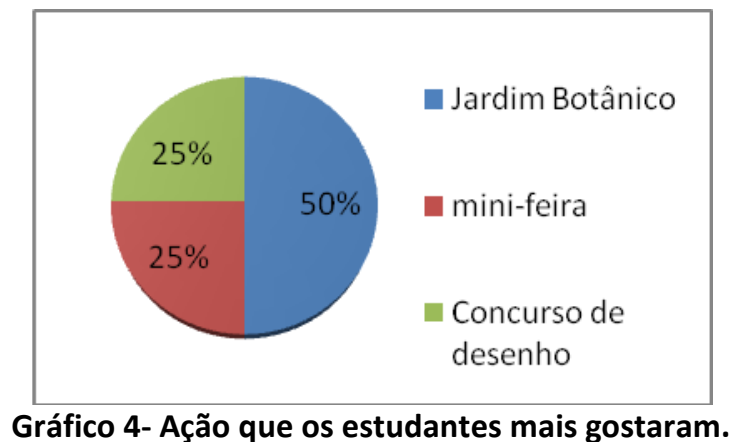

A realização de oficina como o concurso de desenhos permite trabalhar vários aspectos do comportamento e das habilidades dos estudantes. Para os psicólogos pode ser uma ferramenta para compreender melhor a personalidade da criança, o seu lado emocional, bem como demonstrar o que eles estão sentindo. É uma forma de reconhecer e descobrir o talento dos estudantes. Todavia, é importante que os concursos não provoquem apenas o aspecto da competição, que é uma de suas perspectivas, alimentando uma rivalidade nos estudantes. Competição e cooperação são processos sociológicos que podem ser habilmente trabalhados por meio de oficinas dessa natureza.

É necessário ter cuidado para não resumir as ações da COM-VIDA apenas a desenhos, uma vez que os estudantes gostam dessa prática, mas, é preciso trabalhar outras habilidades como a escrita. Então, por que não estimulá-los, por meio de concurso de redação, sobre o Meio Ambiente? Seria uma forma de fazer com que os estudantes escrevessem sobre a 
temática ambiental. Uma atividade como essa pode integrar as ações da COM-VIDA e dos professores da escola em seus vários componentes curriculares.

$\mathrm{Na}$ pergunta que trata sobre o que os estudantes aprendem a partir das ações da COM-VIDA, obtivemos tanto respostas genéricas, como respostas bem específicas. Suas respostas foram: "desenhar" (estudante 1); "muitas coisas" (estudante 2); "reciclar" (estudante 3); e "jardim botânico" (estudante 4). O que mostra que a contribuição da COMVIDA na escola pesquisada ainda é insuficiente, tendo em vista que, como já ressaltamos anteriormente, ela não funciona como deveria. Como podemos perceber no gráfico abaixo sobre o que aprende na COM-VIDA (Gráfico 5).

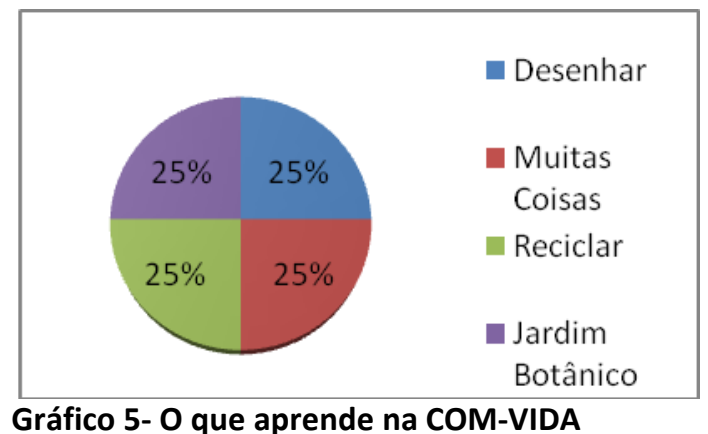

As atividades artísticas podem contribuir para educar ambientalmente o estudante. Trabalhar habilidades com base em desenho, dança, pintura, música, dentre outras, é sempre muito proveitoso. Assim, ao pedir para os estudantes desenharem como eles veem o Meio Ambiente e como esperam que deveria ser, esperamos tê-los sensibilizado para a necessidade de mudar nossas posturas frente ao Meio Ambiente, a exemplo do consumo consciente.

Ao fazerem os desenhos e depois explicarem o que haviam desenhado, isto é, que mensagem eles tentaram transmitir, alguns disseram que, na COM-VIDA, aprendem a fazer reciclagem (na verdade, reutilização). As ações da COM-VIDA possibilitam trabalhar determinados conceitos de forma prática, pois ao dizer "reciclagem" e depois o estagiário esclarecer que se tratava de "reutilização", já que a reciclagem é um processo industrial, isto é, o objeto volta novamente ao ciclo produtivo para ser vendido, enquanto a reutilização é dar outra finalidade a um objeto evitando dele ir para o lixo, o estudante pode compreender de forma prática essa distinção. Dessa forma, mais do que mostrar conceitos é preciso mostrar a diferença na prática, se não os conceitos ficam vazios e não produzem os efeitos esperados. Vale frisar, porém, que nem tudo pode ou deve ser trabalhado de forma prática. Cada prática deve se apoiar em princípios pedagógicos para terem sentido no campo da Educação formal.

\section{CONSIDERAÇÕES FINAIS}

Verificamos que a articulação da comunidade escolar é condição para a promoção da cidadania e desperta o interesse dos estudantes pelos diversos assuntos trabalhados na escola, inclusive os voltados para a questão ambiental. Embora, o documento da COM-VIDA afirme que a participação do projeto deve ser dos estudantes, professores, funcionários e pessoas da comunidade como pai, mãe, avós, entre outros membros da família, foi verificado 
que, em termos práticos, tal articulação ainda é muito frágil e por vezes mesmo inexistente. No caso analisado, verificou-se que há muito ainda a percorrer. Não ocorre efetivamente uma articulação das estratégias de EA da COM-VIDA envolvendo estudantes, professores, gestores, pedagogos e a comunidade.

O sujeito ecológico, como foi dito, não constitui um indivíduo propriamente, mas um conjunto de posturas assumidas pelas pessoas enquanto sujeitos históricos e sociais em relação à temática ambiental. Nesse sentido, identificou-se elementos que levam a essa perspectiva, como foi o caso da gincana proposta pela EMLURB em que os estudantes da COM-VIDA, após o término da gincana, deram continuidade ao processo de separação, além de incentivarem outros estudantes a fazerem o mesmo.

A COM-VIDA pode ser considerada um instrumento para a prática da cidadania ou uma aprendizagem cidadã, tendo em vista que ela estimula os estudantes a serem cidadãos plenos. Essa questão não diz respeito apenas à sociedade civil, mas a todos os indivíduos como cidadãos do mundo, do qual pertencemos. Por isso, devemos assumir a responsabilidade pelas questões ambientais.

Ainda que sejam consideradas positivas, a falta de ação interdisciplinar e de uma abordagem crítica certamente contribuiu para que os estudantes representassem o Meio Ambiente de forma naturalista, isto é, reducionista, ou ainda de forma meramente utilitarista. Por essas visões fragmentadas da realidade, a EA deve ser encarada como Educação em seu sentido mais amplo (com "E" maiúsculo, como utilizamos ao longo deste artigo) e encará-la dessa forma é importante, pois a EA não se trata apenas da junção de um substantivo e um adjetivo.

Outra questão que também é crucial é o incentivo aos estudantes para participarem das decisões relacionadas com as estratégias pedagógicas envolvendo o Meio Ambiente e outros temas.

Por fim, apesar dos problemas verificados, as experiências da COM-VIDA na escola estudada podem ser encaradas, como positivas, na medida em que os problemas identificados podem servir de referências para novas soluções. E ao mesmo tempo indicam novos horizontes e possibilidades didático-pedagógicas da atuação da escola.

\section{REFERÊNCIAS BIBLIOGRÁFICAS}

1. BARDIN, Laurence. Análise de conteúdo. Lisboa: Edições 70, 1977.

2. BOFF, Leonardo. Saber cuidar: ética e compaixão pela terra. 11ạ Ed. Petrópolis, RJ: Vozes, 1999.

3. BRASIL. Constituição da República Federativa do Brasil (1988). Disponível em: www.planalto.gov.br/ccivil 03/constituicao/constituiçao.htm Acesso em novembro de 2010.

4.

. Agenda 21. Ministério do Meio Ambiente, 1992. Disponível em:

www.mma.gov.br/agenda21. Acesso em novembro de 2010.

5. Lei 9.394/96. Lei de Diretrizes e Bases da Educação. 6ạ Ed. Brasília: Senado Federal: Subsecretaria de Edições Técnicas, 2010. 
6. Secretaria de Ensino Fundamental. Parâmetros Curriculares Nacionais: terceiro e quarto ciclos do ensino fundamental - Introdução aos parâmetros curriculares nacionais/ Secretaria de Educação fundamental. Brasília: MEC/SEF, 1998. Disponível em: http://portal.mec.gov.br/:parametros-curriculares-nacionais-5o-a-8o-series.Acesso em janeiro de 2011.

7. Secretaria de Ensino Fundamental. Parâmetros Curriculares Nacionais: terceiro e quarto ciclos do ensino fundamental: Temas transversais/ Meio ambiente/ Secretaria de Educação fundamental. Brasília: MEC/SEF, 1998. Disponível em: http://portal.mec.gov.br/:parametros-curriculares-nacionais-5o-a-8o-series. Acesso em janeiro de 2011.

8. Lei 9.975/99. Educação e consciência ambiental. Brasília: Senado Federal subsecretaria de edições técnicas, 2008 (coleção ambiental v.9).

9. . Ministério da Educação. Secretaria de Educação Continuada, Alfabetização e Diversidade. Formando COM-VIDA: Comissão de Meio ambiente e Qualidade de Vida na escola - construindo a agenda 21 na escola/Ministério da Educação, Ministério de Meio ambiente. 2a ed. Revisada e ampliada. Brasília: MEC, 2007.

10. CAPRA, Fritjof. A teia da vida: uma nova compreensão cientifica dos sistemas vivos. Tradução: Newton Roberval Eichemberg. São Paulo: Cultrix, 2006.

11. CARVALHO, Isabel. Educação ambiental: a formação do sujeito ecológico. 3a. Ed. São Paulo: Cortez, 2008.

12. FAZENDA, Ivani. Interdisciplinaridade: história, teoria e pesquisa. 17ạ. Ed. Campinas, SP: Papirus, 1994. (Coleção Magistério: formação e trabalho pedagógico).

13. GOMES, Bárbara. A formação do sujeito ecológico inserida na formação de professores no curso normal médio. Programa Institucional de Iniciação Cientifica (PIBIC) Graduação/CNPq, IFPE, 2010.

14. GONZALES, Carlos; SILVA, Maclovia. A ética na educação ambiental: as omissões e suas implicações reducionistas. In: Encontro da Associação Nacional de Pós Graduação e Pesquisa em Ambiente e Sociedade (ANPPAS), 2004, Indaiatuba. Anais eletrônicos. Disponível em: http://www.anppas.org.br/encontro anual/encontro2/GT/GT10/carlos gonzales.pdf. Acesso em: 10 de julho de 2011. 
15. GUIMARÃES, Mauro. A dimensão ambiental na educação. 9a. Ed. Papirus, Campinas, SP: 1995.

16. MENDES, Carlos. Projetos pedagógicos em educação ambiental. Curitiba: Fael, 2010. 